HARRAN ÜNIVERSITESI MÜHENDISLIK DERGisi

HARRAN UNIVERSITY JOURNAL OF ENGINEERING

e-ISSN: 2528-8733

\section{HARRAN ÜNIVERSITESİ MÜHENDİSLİK DERGISİ}

HARRAN UNIVERSITY JOURNAL of ENGINEERING

e-ISSN: 2528-8733 (ONLINE)

URL: http://dergipark.gov.tr/humder

\title{
Mühendislik Öğrencilerinin Etik Algıları: Harran Üniversitesi İnşaat Mühendisliği Örneği
}

Engineering Students' Ethical Perceptions:

The Case of Civil Engineering at Harran University, Turkey

Yazar(lar) (Author(s)): Ahmet Sabri ÖĞÜTLÜ ${ }^{1}$, Ali TOKTAŞ²

1 ORCID ID: 0000-0003-1634-0600

2 ORCID ID: 0000-0002-7509-8538

Bu makaleye şu şekilde atıfta bulunabilirsiniz (To cite to this article): Ögütlü A.S., Toktaş A., "Mühendislik Öğrencilerinin Etik Algıları: Harran Üniversitesi İnşaat Mühendisliği Örneği", Harran Üniversitesi Mühendislik Dergisi, 5(3): 205-212, (2020).

Erişim linki (To link to this article): http://dergipark.gov.tr/humder/archive 


Mühendislik Dergisi

\title{
Mühendislik Öğrencilerinin Etik Algıları: Harran Üniversitesi İnşaat Mühendisliği Örneği
}

\author{
Ahmet Sabri ÖĞÜTLÜ ${ }^{1, *}$, Ali TOKTAŞ ${ }^{2}$ \\ ${ }^{1}$ Harran Üniversitesi, Mühendislik Fakültesi, Endüstri Mühendisliği Bölümü, 63300, ŞANLIURFA \\ ${ }^{2}$ Harran Üniversitesi, Mühendislik Fakültesi, İnşaat Mühendisliği Bölümü, 63300, ŞANLIURFA
}

$\ddot{O} z$

Makale Bilgisi

Başvuru: 10/09/2020

Yayln: 25/12/2020

\section{Anahtar Kelimeler}

Etik

Mühendislik Ĕgitimi

Ögrenci Algiları

Inşaat Mühendisliği

Keywords

Ethics

Engineering Education

Student Perceptions

Civil Engineering
Bu çalışmada Harran Üniversitesi Mühendislik Fakültesi İnşaat Mühendisliği öğrencilerinin kendi ve meslektaşlarının etik inançlarını nasıl algıladıklarını belirlemek ve bu iki algı arasında karşılaştırma yapmak amacıyla bir anket çalışması yapılmıştır. Elde edilen veriler SPSS 21.0 paket programına girilmiş ve Wilcoxan İşaretli Sıra Testi ile analiz edilmiştir. Yapılan karşılaştırmalarda cinsiyet, uyruk ve mühendislik etiği ile ilgili ders alma durumu faktörlerinin etkisi incelenmiştir. Araştırmanın bulguları genel olarak öğrencilerin etik davranma konusunda bilinçli olduklarını ve kendilerini akranlarına göre daha etik olarak algıladıklarını göstermiştir. Bayan öğrenciler bu algıyı kısmen sergiledikleri halde, yabancı öğrencilerin algısı farklıdır. Etik dersi alma durumu bu genel algıyı çoğunlukla etkilememiştir. Bu çalışma, inşaat mühendisliği öğrencilerinin mevcut kişisel etik inançları hakkında bilgi sağlamıştır. Öğrencilerin gösterdiği etik bilinç düzeyi inşaat mühendisliği programlarında verilmekte olan etik derslerinin önceki çalışmaların öngörüleri doğrultusunda öğrencileri meslek hayatında etik davranma konusunda cesaretlendireceğini ortaya koymaktadır.

\section{Engineering Students' Ethical Perceptions: The Case of Civil Engineering at Harran University, Turkey}

\begin{abstract}
In this study, a survey was conducted to determine how Harran University Engineering Faculty Civil Engineering students perceive their own and their colleagues' ethical beliefs, and to compare these two perceptions. The obtained data were entered into the SPSS 21.0 package program and analyzed with the Wilcoxan Signed Rank Test. In the comparisons, the effect of the factors of gender, nationality, and course taking status related to engineering ethics was examined. Findings of the research showed that students are generally conscious about behaving ethically and perceive themselves as more ethical than their peers. Although female students partially exhibit this perception, the perception of foreign students is different. Taking ethics lessons mostly did not affect this general perception. This study provided information about the current personal ethical beliefs of civil engineering students. The level of ethical awareness demonstrated by the students reveals that the ethics lessons given in civil engineering programs will encourage students to act ethically in their professional life in line with the foresights of previous studies.
\end{abstract}

\section{GİRIŞ (INTRODUCTION)}

Profesyonel etik, iş hayatında verilen kararların doğruluğunu değerlendirmede yetkililere yardımcı olan kurallardır. Bütün profesyonel mühendisler gibi inşaat mühendislerinin de, aldıkları kararlarda etik kurallara uymak konusunda topluma karşı kişisel ve mesleki yükümlülükleri vardır [1]. Bu nedenle 
mühendislik müfredatında etik eğitimine ilişkin oluşabilecek yetersizliklerin ele alınması önem arz etmektedir.

Mühendislik öğrencilerinin etik konusunda aldıkları eğitimin eksikliğini gidermek amacıyla örneğin Amerika Birleşik Devletleri'ndeki mühendislik lisans programlarının akreditasyonundan sorumlu olan Mühendislik ve Teknoloji Akreditasyon Kurulu (ABET), etik konularının mühendislik lisans müfredatına dahil edilmesini zorunlu kılmıştır [2]. Artık bugün pek çok mühendislik eğitim programında mühendislik etiği dersleri yer almaktadır. Türkiye'deki lisans mühendislik programlarını akredite etmek için kurulan Mühendislik Eğitim Programları Değerlendirme ve Akreditasyon derneği (MÜDEK), etik konularının mühendislik lisans müfredatına dahil edilmesini istemektedir.

Coşkun [3], İnşaat Mühendisliği lisans eğitiminde etik konusunun diğer meslek dersleriyle bütünleştirilerek verilmesinin öğrencilerin bu konudaki farkındalıklarını olumlu yönde etkilediğini ifade etmiştir. Atesh, Ward ve Baruah [4], yüksek öğretimde mühendislik öğrencilerine etik öğretiminin bazı etkili yollarına değinmiştir.

Bununla birlikte etiğin öğretilemeyeceğini öne süren bazı çalışmalar da vardır [5,6]. Abaté [7], mühendislik etiğgi öğretiminin mühendislik öğrencilerini daha ahlaklı kılmayacağını ve etik öğretiminin bu amaçla kullanılamayacağını ve kullanılmaması gerektiğini ifade etmiştir. Bu çalışmalar etiğin öğretilemeyeceği sonucuna varmasına rağmen, etik muhakemenin öğretilebileceğini öne sürmektedir. Bu bakış açısı genellikle, ağırlıklı olarak soyut etik yapılara ve ahlaki gerekçelendirmeye odaklanan etik eğitimine yol açar [8,9], böyle bir teorik yaklaşımın mühendislik faaliyetleri bağlamında ele alınmasının mühendislik öğrencileri için etkili bir öğretim şekli olacağını söylemiştir. Bu durumda, genellikle mesleki davranış kural ihlallerini vahim sonuçlarıyla birlikte detaylandıran bir dizi vaka çalışması kullanmanın profesyonel mühendislik etiği öğretimine yönelik geleneksel yaklaşım olduğu belirtilmektedir. Fakat genel olarak bu yaklaşımın öğrencilerin etik gelişimi üzerinde çok az etkiye sahip olduğu gösterilmiştir[6]. Büyük hataların grafiksel sunumları, sonuçlarına ilişkin hikayeler ve etik kod ilkelerinin sağladığı sağlam çerçevenin kalıcı bir izlenim bırakabildiği ifade edilmiştir. Ancak öğrenciler mesleki kimliklerini genellikle yakınlarından ve meslektaşlarından alırlar [10]. Öğrencilerin mesleki etikleri çoğunlukla kişisel etiklerinin bir uzantısı olarak görülmüştür. Bu nedenle müfredatta yer alan etik ögretiminin tamamen mühendislik odaklı olması gerekmediği, öğrencilerin mümkün olduğunca etik profesyonel mühendislik rol modellerine maruz bırakılması gerektiği ve bunun biçimsel ders veya özel ders şeklinde olabileceği, ancak mühendislik danışmanlığı ve etik davranışların akademik mühendislik personeli tarafından modellenmesi şeklinde olduğunda çok daha faydalı olabileceği belirtilmiştir [8]. Bununla birlikte etik ve ahlaki gelişim üzerine yapılan bazı çalışmalar, profesyonel mühendislik etiği eğitiminin öğrencilerin etik davranma eğilimini güçlendirdiğini ortaya koymuştur [10-12].

Bazı demografik faktörlerin öğrencilerin etik algısını etkileyebileceğini gösteren çalışmalar bulunmaktadır. Zambiya inşaat endüstrisindeki etik olmayan davranışların yaygınlığına ilişkin öğrenci algılarını araştıran bir çalışma [13], öğrenim yılı ve programı dikkate alındığında, etik olmayan uygulamalara ilişkin alg1 farklılıklarının bu demografik gruplar için belirgin olduğunu göstermiştir. Aydemir ve Demirci [14], Türk üniversite öğrencilerinin etik algılarını ve cinsiyet, sınıf, gelir, akademik dal ve iş deneyiminin etik algılar üzerindeki etkisini incelemiştir. Öğrencilerin etik algıları ile öğrencilerin bazı demografik özellikleri arasında bir ilişsi olduğunu belirlemiştir. Fatoki ve Marembo [15] ABD'deki öğrencilerin etik algılarını analiz etmişlerdir. Öğrencilerin cinsiyetinin, eğitim seviyesinin ve uyruğunun etkisini dikkate almışlardır. Farklı eğitim seviyesindeki öğrenciler arasında etik uygulamaların algılanmasında önemli bir fark olduğunu belirlemişlerdir. Cinsiyet veya uyruk dikkate alındığında önemli farkl11ıklar gözlemlenememiştir. Steele vd. [12], ABD'deki lisansüstü öğrencilerin ve ABD'de okuyan uluslararası öğrencilerin etik algılarını karşılaştırmış ve öğrencilerin uyruğunun öğrencilerin etik algıları üzerinde önemli bir etkisi olduğu sonucuna varmıştır. İki grupla yapılan bir odak grup çalışması etik eğitimine katılan bir grup ile katılmayan bir grup arasında etik karar verme konusunda önemli bir farklılık olmadığını ortaya koymuştur. Bununla birlikte, karar verme sürecinde "eğitimli" grup "eğitimsiz" gruptan daha tutarlı davranış göstermiştir [4].

Stappenbelt ahlaki muhakeme yapıları ve profesyonel davranış kuralları üzerine verilen eğitimin, halihazırda sahip olunan kişisel etik ve ahlaki inançlara göre hareket etme konusunda cesaret verici olacağını belirtmiştir. Bu durumda mühendislik öğrencilerinin ne kadar etik oldukları ve kişisel etik 
gelişimini ilerletmek ve teşvik etmek için neler yapılabileceği ile ilgili soruya odaklanmıştır. O'Clock ve Okleshen [16] tarafından mühendislik ve işletme lisans ve yüksek lisans öğrencilerinin kişisel etik inançlarını inceleyen çalışma, bu sorularla ilgili bazı bilgiler sağlamıştır. İşletme öğrencileri genellikle daha az etik davranışa yönelik bir önyargı ve diğer disiplinlerden öğrencilere göre daha az gelişmiş etik değerler sergilemiştir. Ayrıca bu araştırma, işletme ve mühendislik öğrencilerinin etik algıları ve davranışları arasında önemli bir istatistiksel fark olmadığını bildirerek, mühendislik öğrencilerinin etik değerlerinin belki de işletme dışındaki disiplinlerdeki akranlarından daha az gelişmiş olduğunu göstermiştir.

Bununla birlikte, bu çalışma MBA eğitimi almak için lisansüstü çalışmalara dönen mühendislik ve işletme öğrencileri arasında belirgin bir fark olduğunu da bildirmektedir. Lisansüstü mühendislik öğrencileri, lisans öğrencilerine kıyasla önemli ölçüde daha yüksek düzeyde etik değerler ve davranışlar sergilemiştir. Lisansüstü işletme öğrencileri, daha düşük bir etik değer ve davranış düzeyi göstererek tam tersi bir eğilim sergilemiştir. Bununla birlikte, Buckeridge [17] genç mühendislerde net bir ahlaki perspektif eksikliğine ilişkin genel bir algı olduğunu ve son yıllarda mühendislik mezunlarında etik farkındalık azalmasının buna eşlik ettiğini açıklamıştır.

Etik farkındalıkta algılanan bu düşüşün geçerli mi yoksa yanıltıcı mı olduğunu değerlendirmek için, Stappenbelt Avustralya mühendislik öğrencilerinin kişisel etik değerlerinin mevcut durumunu ve profesyonel mühendisler de dahil olmak üzere başkaları hakkındaki inançlarını ortaya koyan bir çalışma yapmıştır. Bu çalışmada öğrenciler etik dışı davranışları genel olarak etik dışı olarak algılamıştır. Bununla birlikte etik dışı davranışlarda kendi ve akran algısı arasındaki fark tutarlı bir seyir izlememiştir. Öğrenciler bazı davranışlarda kendilerini akranlarına göre daha etik olarak algılarken bazı davranışlarda akranlarını daha etik olarak algılamışır. Çalı̧̧madaki en dikkat çekici sonuçlardan biri "alanınızla ilgili son gelişmeleri takip etmemek" maddesinin öğrenciler tarafindan "biraz etik dışı" davranış olarak değerlendirilmesidir. Stappenbelt bu sonucu, mühendislik müfredatındaki yaşam boyu öğrenmeyle ilgili lisansüstü yeterliliklerin daha da güçlendirilmesi gerekliliğine bir işaret olarak yorumlamıştır.

$\mathrm{Bu}$ çalışmada etik farkındalıktaki bahsedilen gerilemenin Türkiye'deki mühendislik öğrencilerinde de geçerli olup olmadığını belirlemek amaçlanmıştır. Bu amaç doğrultusunda öğrencilerin kendilerine ve meslektaşlarına ilişkin etik algılarını ortaya koymak ve aralarında karşılaştırma yapmak için Harran Üniversitesi Mühendislik Fakültesi İnşaat Mühendisliği öğrencileri üzerinde bir anket çalışmas1 yapılmıştır. Ayrıca karşılaştırmalarda cinsiyet, uyruk ve mühendislik etiği ile ilgili ders alma durumu etmenleri de göz önünde bulundurulmuştur.

\section{YÖNTEM}

Harran Üniversitesi Mühendislik Fakültesi İnşaat Mühendisliği bölümünde örgün eğitim gören öğrencilerin kişisel etik algılarını incelemek için bir anket çalışması yürütülmüştür. Bu amaçla 204 tane ikinci sınıf öğrencisinden planlanan tarih aralığında anket ile veri toplanmıştır. Araştırmaya katılan öğrencilerin yaklaşık \%9'u yabanc1 \%91'i T.C. uyruğuna sahiptir. Toplanan veri SPSS 21.0 paket programına girilmiş ve analiz edilmiştir. Analiz aşamasında, öğrencilerin kendilerine ilişkin etik algıları ile meslektaşlarına dair etik algıları ankette yer alan davranışlar bazında karşılaştırılmıştır. Karşılaş̧ırmalarda cinsiyet, uyruk ve mühendislik etiği dersini alma durumu etmenleri de göz önünde tutulmuştur. Karşılaştırmalarda parametrik test koşulları sağlanmadığından parametrik olmayan testlerden Wilcoxan İşaretli Sıra Testi uygulanmıştır. Testlerde anlamlılık düzeyi \%5 olarak kabul edilmiştir.

Ankette yer alan davranışlar Stappenbelt tarafından yapılan çalışmadan alınmıştır. Davranış listesi ve ölçeklendirme Tablo 1'de verilmiştir. Öğrenciler on altı adet davranışın her biri için hem kendi inançlarını hem de meslektaşlarına dair inançlarını değerlendirmiştir. Öğrencilerin her bir davranışı ne kadar etik dışı bulduğunu ve meslektaşlarının her bir davranışı ne kadar etik dışı bulacağını değerlendirmeleri istenmiştir. 
Tablo 1: Ankette yer alan davranış listesi ve ölçeklendirme

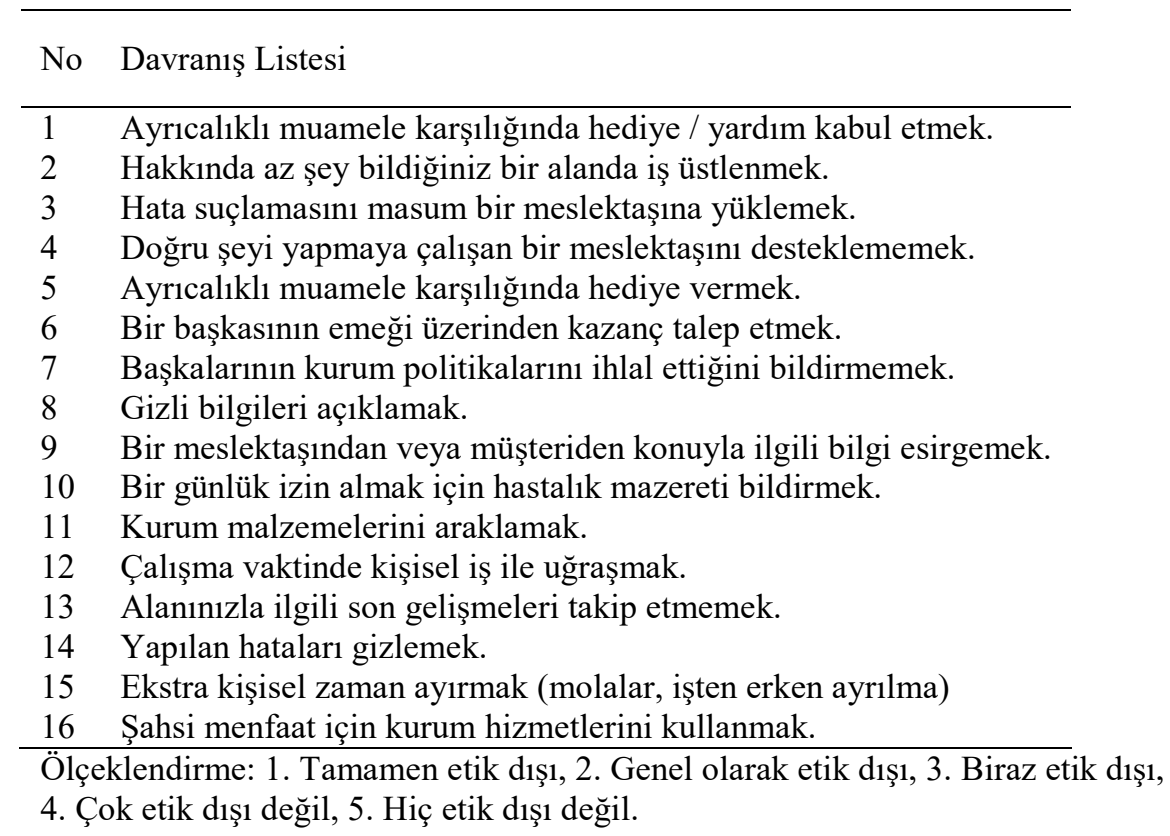

\section{BULGULAR VE TARTIŞMA}

Davranış bazında yapılan karşılaştırmalarda tespit edilen istatistiksel olarak anlamlı farklılıklar Tablo2'de verilmiştir. Anket listesindeki bütün davranışlar için öğrencilerin kendi ve meslektaş algıları arasındaki farklılıklar istatistiksel olarak anlamlı bulunmuştur. Bu farklılıkların yönü tutarlıdır. Yani, bütün davranışlarda öğrenciler kendilerini meslektaşlarına göre daha etik olarak değerlendirmiştir. Benzer sonuç TC uyruklu öğrenciler için de geçerlidir. Bu, O'Clock ve Okleshen tarafından yapılan çalışmanın sonucu ile paraleldir. Söz konusu çalışmada "kendilerini" akranlarına göre tutarlı ve anlamlı olarak daha etik olarak değerlendiren öğrenciler arasında belirgin olan "halo" etkisi bu çalışmada da görülmüştür. Bu sonuç Türkiye ile Birleşik Devletler arasında etik konusundaki bakış açısının benzer olduğuna işaret etmektedir.

Şekill'de araştırmaya katılan öğrencilerin kendi ve meslektaş algılarına ilişkin ortalama puanları gösterilmiştir. Şekle bakıldığında katılımcılar genel olarak söz konusu davranışları etik dışı olarak algılamışlardır. Öğrencilerin en etik dışı olarak puan verdiği davranışlar 3-"hata suçlamasını masum bir meslektaşına yüklemek", 11-"kurum malzemelerini araklamak.", 6- "bir başkasının emeği üzerinden kazanç talep etmek", 8- "gizli bilgileri açıklamak" olmuştur.

Öğrenciler tarafından en az etik dışı olarak puanlanan davranış 10-" bir günlük izin almak için hastalık mazereti bildirmek" maddesidir. Bu maddeyi sırasıyla 13- "alanınızla ilgili son gelişmeleri takip etmemek" ve 14-" yapılan hataları gizlemek" izlemiştir. Madde 13'ün öğrenciler tarafından en az etik dış1 davranışlardan biri olarak değerlendirilmesi, mühendislik müfredatındaki yaşam boyu öğrenmeyle ilgili lisansüstü yeterliliklerin güçlendirilmesi gerekliliğine işaret etmektedir [8]. 
Tablo 2: Kendi ve meslektaş algısı arasındaki farklılıklar.

\begin{tabular}{llllllll}
\hline \multirow{2}{*}{ Davranışlar } & \multirow{2}{*}{ Genel } & \multicolumn{3}{c}{ Cinsiyet } & \multicolumn{2}{c}{ Uyruk } & \multicolumn{2}{c}{ Etik Dersi } \\
\cline { 2 - 7 } & & Erkek & Bayan & TC & Diğer & Evet & Hayır \\
\hline 1 & + & + & + & + & - & + & + \\
2 & + & + & - & + & - & + & + \\
3 & + & + & + & + & - & + & + \\
4 & + & + & - & + & - & + & + \\
5 & + & + & - & + & - & + & + \\
6 & + & + & + & + & - & + & + \\
7 & + & + & + & + & - & + & + \\
8 & + & + & - & + & - & + & + \\
9 & + & + & + & + & - & + & + \\
10 & + & + & + & + & - & - & + \\
11 & + & + & - & + & - & + & + \\
12 & + & + & + & + & - & + & - \\
13 & + & - & - & + & - & - & + \\
14 & + & + & + & + & - & + & + \\
15 & + & + & - & + & - & + & + \\
16 & + & + & - & + & - & + & + \\
\hline+
\end{tabular}

+ işareti istatistiksel olarak anlamlı farklılıkları gösterir.

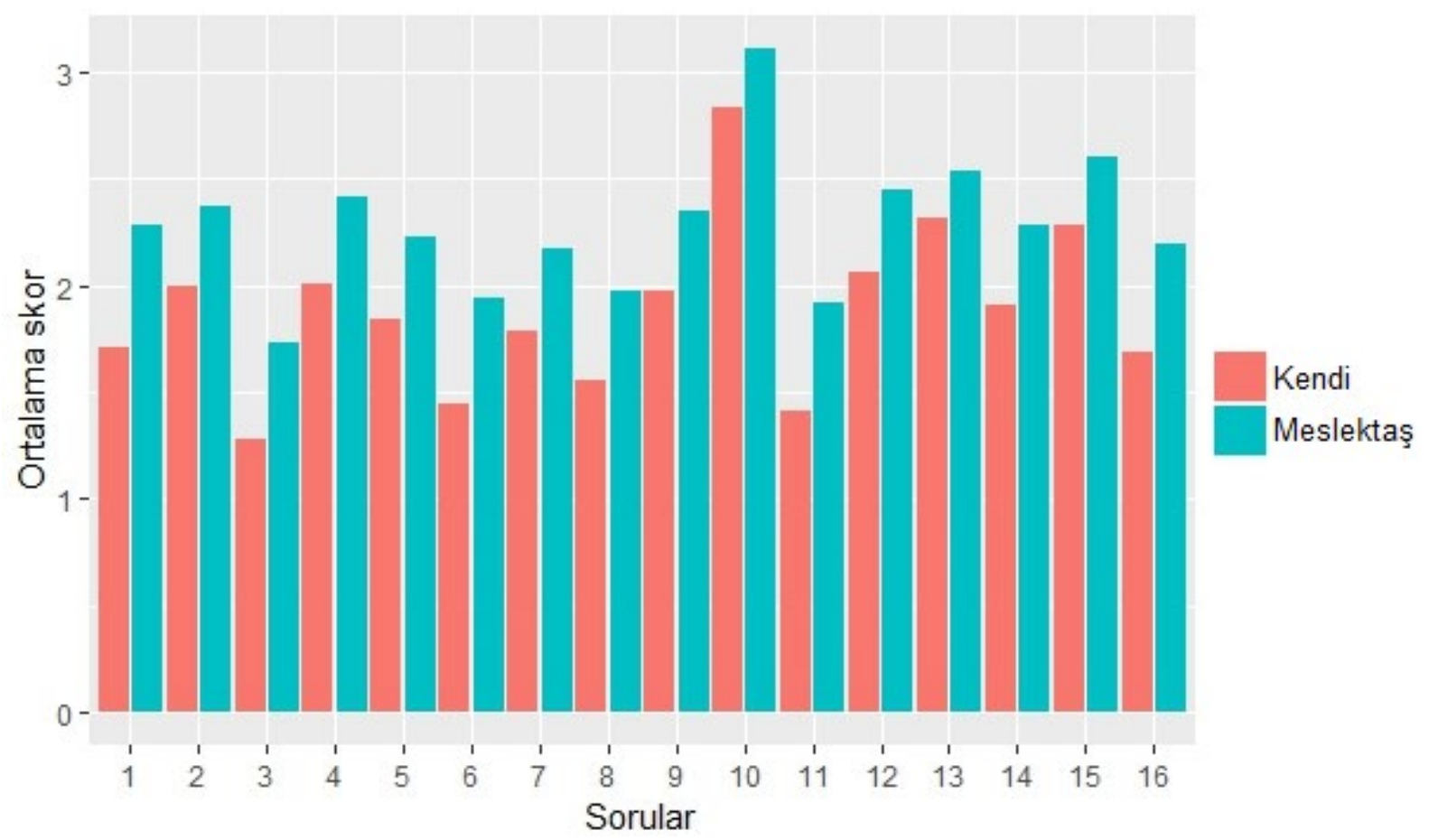

Şekil 1: İņ̧aat mühendisliği öğrencilerinin davranış bazında kendi ve meslektaş algılarına ilişkin ortalama skorları (Genel)

Araştırmaya katılan öğrencilerin cinsiyet, uyruk ve etik dersi alma durumunun alt kategorileri için kendi ve meslektaş algılarına ilişkin ortalama skorlar Şekil2'de gösterilmiştir.

Erkek öğrenciler için 13- "alanınızla ilgili son gelişmeleri takip etmemek" maddesi dışındaki bütün davranışlarda genel tabloya uygun olarak kendi ve meslektaş algıları arasındaki farklılıklar istatistiksel olarak anlamlıdır. İlgili maddede anlamlı farklılık tespit edilememiştir. Bayan öğrenciler için maddelerin yarısında (2-4-5-8-11-13-15-16) genel tabloya uygun olarak kendi ve meslektaş algıları arasındaki farklılıklar istatistiksel olarak anlamlıdır. Diğer maddelerde anlamlı farklılık söz konusu değildir. 
Araştırmaya katılan TC uyruklu öğrenciler için bütün davranışlarda kendi ve meslektaş algıları arasındaki farklılıklar istatistiksel olarak anlamlıdır. Bu öğrenciler genel tabloya uygun olarak "kendilerini" akranlarına göre tutarlı ve anlamlı olarak daha etik olarak değerlendirmiştir. Daha önce bahsedilen "halo" etkisi araştırmaya katılan yabancı öğrenciler için geçerli değildir. Bu öğrenciler için tüm maddelerde kendi ve meslektaş algıları benzerdir.

Etik dersi alan öğrenciler için 10-"bir günlük izin almak için hastalık mazereti bildirmek" ve 13"alanınızla ilgili son gelişmeleri takip etmemek" maddeleri dışındaki tüm davranışlarda kendi ve meslektaş algıları arasındaki farklılıklar istatistiksel olarak anlamlıdır. Bu davranışlarda öğrenciler kendilerini meslektaşlarına göre daha etik olarak değerlendirmiştir. Diğer iki davranış için anlamlı bir farklılık tespit edilmemiştir. Etik dersi almayan öğrenciler için 12. madde dışındaki tüm davranışlarda öğrenciler kendilerini meslektaşlarına göre daha etik olarak değerlendirmiştir. 12-"çalışma vaktinde kişisel iş ile uğraşmak" maddesinde kendi ve meslektaş algıları arasındaki farklılıklar istatistiksel olarak anlamlı bulunmamıştır.

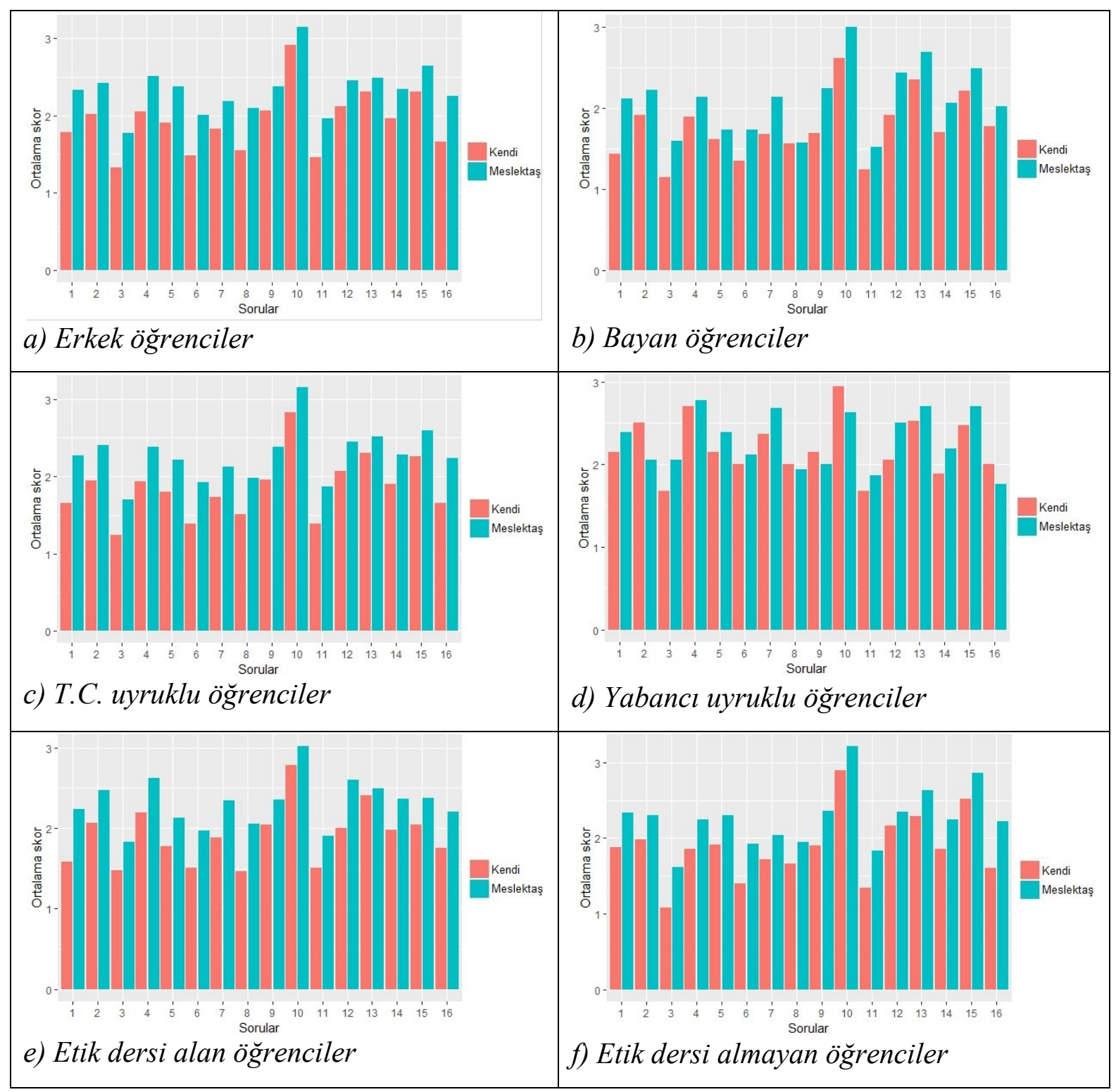

Şekil 2: Cinsiyet, uyruk ve etik dersi alma durumunun alt kategorileri için kendi ve meslektaş algilarına ilişkin ortalama skorlar. 


\section{SONUÇ}

Bu çalışma, inşaat mühendisliği öğrencilerinin mevcut kişisel etik inançları hakkında bilgi sağlamıştır. Genel olarak, örneklem grubundaki mühendislik öğrencileri ankette listelenen eylemlerin etik dişı olduğu konusunda hemfikir olmasına rağmen, endişe uyandıran birkaç madde belirlenmiştir. Özellikle, "alanınızla ilgili son gelişmeleri takip etmemek" maddesi öğrenciler tarafindan en az etik olmayan davranışlardan biri olarak değerlendirilmiştir. $\mathrm{Bu}$ sonuç, daha önce ifade edilen mühendislik müfredatındaki yaşam boyu öğrenmeyle ilgili lisansüstü yeterliliklerin daha da güçlendirilmesi ihtiyacını vurgulamaktadır. $\mathrm{Bu}$ çalışmada, öğrencilerin etik algıları ile meslektaşlarının inançlarına ilişkin algıları arasında önemli bir fark olduğu gözlenmiştir. Bütün davranışlarda öğrenciler kendilerini meslektaşlarına göre daha etik olarak değerlendirmiştir. Erkek öğrenciler "alanınızla ilgili son gelişmeleri takip etmemek" maddesi dışındaki bütün maddelerdeki değerlendirmeleri genel tabloya uygundur. İlgili maddede erkek öğrencilerin kendi ve meslektaş algıları farklı değildir. Bayan öğrenciler davranışların yarısında kendilerini meslektaşlarına göre daha etik olarak algılamışlardır. Diğer maddelerde anlamlı bir farklılık belirlenmemiştir. T.C. uyruklu öğrencilerin değerlendirmeleri genel tabloya paralel olduğu halde, yabanc1 öğrenciler için durum farklıdır. Bu öğrenciler için tüm maddelerde kendi ve meslektaş algıları arasında farklılık görülmemiştir. Bu durum akran algısının T.C. uyruklu öğrencilerde yabancı öğrencilerden farklı olduğunu göstermektedir. Etik dersi alanlarda iki, almayanlarda bir madde dişında tüm öğrenciler kendilerini meslektaşlarına göre daha etik olarak değerlendirmiştir. Söz konusu üç madde için anlamlı bir farklılık söz konusu değildir. Sonuç olarak, öğrencilerin genel olarak sergiledikleri etik bilinç düzeyi, inşaat mühendisliği programlarında verilmekte olan etik derslerinin önceki çalışmaların öngörüleri doğrultusunda öğrencileri meslek hayatında etik davranma konusunda cesaretlendireceğini göstermektedir. Bu çalışmanın diğer mühendislik programlarını içerecek şekilde tekrarlanması elde edilen sonuçların çıkarsama alanını genişletecektir.

\section{TEŞEKKÜR}

Bu çalışma TÜBİTAK 2209-A üniversite öğrencileri yurt içi araştırma destek programı kapsamında yürütülmüştür.

\section{ÇIKAR ÇATIŞMASI}

Makale yazarları aralarında herhangi bir çıkar çatışması olmadığını beyan ederler.

\section{KAYNAKLAR}

[1] M. Usmen, S. Baradan ve Ö. Akboğa, İnşaat Mühendisliğinde Etik: Amerika Birleşik Devletleri Örneği. Engineering Sciences, 7: 1 (2012) 341-349.

[2] C. B. Fleddermann, Engineering ethics, Upper Saddle River, NJ: Prentice Hall, 1999.

[3] H. Coşkun, Mühendislik Öğrencilerinin İş Etiği Konusundaki Farkındalıklarının Belirlenmesi ve Geliştirilmesi. 4.İnşaat Yönetimi Kongresi, TMMOB-İMO İstanbul Şubesi, 2007.

[4] M. Atesh, T. Ward, ve B. Baruah, Analyzing the perception, judgment and understanding of Ethics among Engineering students in Higher Education. In 2016 15th International Conference on Information Technology Based Higher Education and Training (ITHET) (pp. 1-7). IEEE, 2016.

[5] N. Steneck, Designing Teaching and Assessment Tools for an Integrated Engineering Ethics Curriculum. 29th ASEE/IEEE Frontiers in Education Conference, 12-17, 1999.

[6] C. Bauer, V. D. Adams, Who Wants to Be An Ethical Engineer? 35th ASEE/IEEE Frontiers in Education Conference, Indianapolis, USA, 2005.

[7] C. Abaté, Should Engineering Ethics be Taught? Science and Engineering Ethics, 17: 3 (2011) 583596. 
[8] B. Stappenbelt, Ethics in engineering: student perceptions and their professional identity. JOTSE: Journal of technology and science education, 3: 1 (2013) 3-10.

[9] W. Lynch, Teaching Engineering Ethics in the United States. IEEE Technology and Society Magazine, 27-36, 1997.

[10] M. C. Loui, Ethics and the Development of Professional Identities of Engineering Students. Journal of Engineering Education, 94: 4 (2005) 383-390.

[11] P. C. Ooi, M. T. Tan, Effectiveness of workshop to improve engineering students' awareness on engineering ethics. Procedia-Social and Behavioral Sciences, 174 (2015) 2343-2348.

[12] L. M. Steele, J. F. Johnson, L. L. Watts, A. E. MacDougall, M. D. Mumford, S. Connelly ve T. L. Williams, A comparison of the effects of ethics training on international and US students. Science and Engineering Ethics, 22: 4 (2016) 1217-1244.

[13] S. Zulu, F. Muleya, A student perspective of ethics in the Zambian construction industry. Journal of Engineering, Design and Technology, 17: 2 (2019) 266-282.

[14] M. Aydemir, M. K. Demirci, Ethical perceptions of the future leaders: a case of a Turkish universty. International Journal of Emerging and Transition Economies, 1: 1 (2008) 163-175.

[15] O. Fatoki, M. Marembo, An investigation into the attitudes toward business ethics by university students in South Africa. African Journal of Business Management, 6: 18 (2012) 5865-5871.

[16] P. O'Clock, M. Okleshen, A comparison of ethical perceptions of business and engineering majors. Journal of Business Ethics, 12: 9 (1993) 677-687.

[17] J. Buckeridge, Do engineers still move mountains?: A "new world" appraisal in light of ethics, engineering, economics and the environment. Australasian Association for Engineering Education Conference 2011: Developing engineers for social justice: Community involvement, ethics \& sustainability 5-7 December 2011, Fremantle, Western Australia. pp. 7-12, 2011. 